\title{
Corporate ethics, governance and social responsibility in MENA countries
}

\author{
Walid ElGammal \\ Department of Finance and Accounting, Lebanese American University, \\ Beirut, Lebanon \\ Abdul-Nasser El-Kassar \\ Department of Information Technology and Operations Management, \\ Lebanese American University, Beirut, Lebanon, and \\ Leila Canaan Messarra \\ Department of Management Studies, Lebanese American University, \\ Beirut, Lebanon
}

\begin{abstract}
Purpose - Studies show that corporate governance (CG) and corporate social responsibility (CSR) are driven by ethical practices. The relationships between corporate ethics, CG and CSR have been heavily studied indicating significant associations. The purpose of this paper is to examine the mediating role of CG on the relationship between ethics and CSR.

Design/methodology/approach - Data were collected through questionnaires from small to medium-sized enterprises (SMEs) in the Middle East and North Africa (MENA) countries. The results were analyzed using structural equation modeling.

Findings - The results indicate that ethical practices have positive impact on CG, and in turn CG has a positive impact on CSR. The results also reveal a mediating effect of CG on the relationship between ethics and CSR. Research limitations/implications - The sample selected is based on two countries in the MENA region, Egypt and Lebanon. Only SMEs are considered.

Practical implications - The innovative capabilities of SMEs in developing and emerging economies could be enhanced through corporate ethical practices which guide management for more CSR engagement through good CG.

Originality/value - The study contributes to corporate ethics, CG and CSR literature by providing evidence from a significant region, with both developing and emerging economies, on the mediating role of $\mathrm{CG}$ on the relationship between ethics and CSR.
\end{abstract}

Keywords Corporate governance, Ethics, Corporate social responsibility, MENA region

Paper type Research paper

\section{Introduction}

The topic of corporate governance (CG) has attracted multidisciplinary researchers from fields such as law, political sciences, accounting, finance, economics and even philosophy. In a corporate setting, the implementation of an effective CG system is not as easy as it may appear, with ongoing challenges to maintaining it and reaching the desired goals. The existence of CG governs the relationships between the management and the firm's stakeholders (Gebba, 2015).

(C) Maheshwaran Gopalakrishnan. Published by Emerald Publishing Limited. This article is published under the Creative Commons Attribution (CC BY 4.0) licence. Anyone may reproduce, distribute, translate and create derivative works of this article (for both commercial and non-commercial purposes), subject to full attribution to the original publication and authors. The full terms of this licence may be seen at: http://creativecommons.org/licences/by/4.0/legalcode

The work was performed within Sustainable Production Initiative and the Production Area of Advance at Chalmers. The authors would like to thank VINNOVA for their funding of StreaMod research project.
Corporate ethics, CG and CSR in MENA countries

Received 31 March 2017 Revised 24 August 2017 Accepted 13 September 2017 
$\mathrm{MD}$

56,1

As a result, the importance of $C G$ and the awareness about it were rising in the last few decades with the aim to protect and secure all stakeholders interests while ensuring the company's economic efficiency and leading to sustainability (Crowther, 2008; Grant, 2003). Under CG practices, there lie several categories and components which usually indicate the level of CG in a company. One such component is the ownership structure which mainly focuses on the board of directors' practices and its established committees.

On the other hand, the ownership structure only does not guarantee an effective CG system. This requires three distinct characteristics in a company: accountability, responsibility and transparency. The presence of these traits is the duty of the management, the board of directors and the audit committee toward the investors and all other stakeholders. While many interrelate CG with ethics and morals (Trong, 2012), it is crucial to have an internationally acceptable guidelines and ethical behaviors upon building up a CG system. For a business to be considered ethical, it has to balance between both pursuing profit and fulfilling social responsibilities. In this sense, morals and standards may vary according to culture and region. In the Middle East and North Africa (MENA) region, 85 percent of business entities are small to medium-sized enterprises (SMEs) and family-owned enterprises (FOEs) (Saïdi, 2004), where CG practices have yet not reached a saturated level, and are still challenged by both external and internal factors. In such a significant region, SMEs seek to achieve and sustain innovation capabilities through the combination of inventive entrepreneurial processes which lead to the creation of new economic value.

SMEs play a major role for economies both locally and globally. It is important to mention that these enterprises can contribute to the economic growth, employment, development, production and innovation (Cans1z, 2008). With their flexible structures, small to medium enterprises are capable of meeting various demands in diverse markets and even create economic activities. It is important to mention that accountability, social responsibility, transparency and fairness are factors required to operate in international markets. These requirements coupled with a profound CG would allow both SMEs and societies to flourish. Corporate values such as shareholder value, business ethics and corporate social responsibility (CSR) attract a lot of attention.

Moreover, sound CG practices have a direct effect on the economy; they are capable of attracting investment to the MENA region, given that they improve efficiency of management in companies and decrease risk. Digging deeper, the banking and financial services sectors play a pivotal in the implementation of the mentioned CG performs as they provide the primary means of business financing. These practices, if implemented properly, would enable the countries of the region to modernize corporate sectors, attract technology and foreign investment and thus boost the overall economic performance of the region.

CSR is a firm-wide approach that defines how much an organization contributes back to the society and utilizes its available resources in a responsible manner, contributing to sustainable development through conveying benefits such as social, economic and environmental to stakeholders. While some considered CSR as an antecedent to CG (Trong, 2012), Jo and Harjoto (2012) studied the direction of causation between CG and CSR and found that CG has a positive effect on CSR. This direction of causation is considered in most research involving the relationship between CG and CSR (for instance, Ben Barka and Dardour, 2015; Sariannidis, 2014).

CG and CSR were also linked to innovation (Rexhepi et al., 2013; Bocquet et al., 2013; Cantista and Tylecote, 2008; Luo and Du, 2015). Gallego-Alvarez et al. (2011) examined the bidirectional relationship between CSR and innovation. Hence, the innovative capabilities of SMEs in developing and emerging economies could be enhanced through corporate ethical practices which guide management for more CSR engagement through good CG.

Accordingly, the purpose of this study is to examine the impact of ethical practices on both CG and CSR, as well as the impact of CG on CSR. Data were collected from SMEs operating in MENA region (Lebanon and Egypt). The targeted population was chosen based on the fact 
that most of the larger companies are expected to already have established good CG practices as well as a code of ethics. The study contributes to corporate ethics, CG and CSR literature by providing evidence from a significant region, with both developing and emerging economies, on the mediating role of CG on the relationship between ethics and CSR.

The reminder of this paper is organized as follows. A review of the literature is presented in Section 2. The theoretical framework, the development of the hypotheses and the conceptual model are given in Section 3. The methodology and data analysis are discussed in Section 4. Limitations, suggestions for future studies and conclusions are presented in Sections 5 and 6.

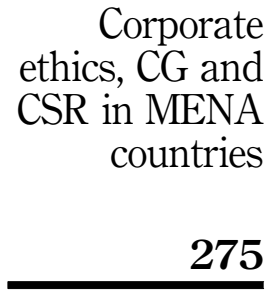

\section{Literature review}

\section{$2.1 C G$}

It is well known that CG has various definitions since it is tackled from opposing viewpoints; however, it is universally agreed upon that CG plays a fundamental role in distributing responsibilities and resources in a firm in order to affect strategic choices and create value within the respective entity and across countries (Aguilera Florackis and Kim, 2016). Not only this, CG is also defined as a set of laws and rules that regulate the legitimacy of firms' activities. With the occurrence of several business failures, scandals and the financial crisis later, Claessens and Yurtoglu (2013) explain that such lack of successes are just indicators of several structural reasons that explain why CG became of superior prominence for well-being and economic development. For example, the financial crisis of 2008 reinforced how CG failures can not only ruin corporations, but also adversely disrupt whole economies (Claessens and Yurtoglu, 2013).

In the light of the financial crisis, many comments targeted $\mathrm{CG}$, concentrating on enterprises' activities being vital to the community and economy grossly. However, relatively small disclosure was directed toward the role of CG especially in governments, which also has a major impact on the society (Wadie, 2011). For example, Habbash (2016) tackled the effect of CG regulations in the Kingdom of Saudi Arabia, and the analysis caused significant positive correlations between government ownership, family ownership, firm size and age and CSR disclosure. For CG regulators, all results in Habbash (2016) study confirm that the application of Saudi CG code in 2007 maybe one of the reasons for an improved CSR disclosure. The regulators also recognize the role that governments and families can play enhancing disclosure, by default benefiting the enterprise as whole, and the community as a result. Moreover, Habbash (2016) moves on to add that stakeholders can exert pressure on managerial levels to disclose extra social information, given the disclosure average is fairly low.

One of the most popular definitions of CG introduced by the Cadbury Committee (1992) is that it is "the system by which companies are directed and controlled." For Shleifer and Vishny (1997), this CG system "deals with the ways in which suppliers of finance to corporations assure of getting a return on their investment," whereas the mechanisms of CG are the legal and economic institutions that can be changed through political process (Shleifer and Vishny, 1997). Therefore, the market structure, the judicial system and the economic form of the country do highly influence the CG system adopted by the companies operating in the country. As a result, Denis and McConnell (2003) characterized governance mechanisms to the firm as either internal or external. The internal governance mechanisms consist of the board of directors and ownership structure, while the external mechanisms are reflected by the takeover market and the legal system (Denis and McConnell, 2003).

On the other hand, good CG system allowed firms to gain a variety of benefits, including lower cost of capital, better performance and easier access to external financing in addition to a favorable treatment of all stakeholders (Claessens and Yurtoglu, 2013). Adding to this, the well-being of employees is also integrated in good CG systems, which directly links CG with the broad concept of CSR. All these benefits ensure greater creation of employment and wealth in general, and thus an improved and more developed economy. Furthermore, the topic 
of CG is not a point of interest for academics only, but also for practitioners and legal bodies who play a significant role in creating, communicating, monitoring and improving CG practices and mechanisms around the world. The Organization for Economic Co-operation and Development (OECD) is one of oldest and highly active organization concerned in setting and promoting policies along with solutions for better economic and social well-being of people; it includes a membership of 35 countries. For OECD, CG continues to be a major issue since its establishment of the CG principles in 1999. These principles were then revised in 2004 and recently in September 2015. "Good corporate governance is not an end in itself. It is a means to support economic efficiency, sustainable growth and financial stability [...] and helps ensure that shareholders and other stakeholders who contribute to the success of the corporations are treated fairly" (OECD, 2015). We can say then that the OECD is an "external governance" player as it deals with regulators, policy makers and governments in addition to businesses, knowing that no single CG principles and rules can be adopted in all countries, and thus the principles are more considered as a framework and guidelines by the OECD. According to Dahawy (2008), the following four categories mainly add to the success of the CG: transparency of financial data, analysis of the ownership structure and control privileges, structure of the board of directors and management and analysis of auditing committee.

\subsection{Transparency of financial data}

As accounting is the language of business, the need for a clear and fair representation of the firm's standing becomes a must. In light with many scandals and fraud actions, financial reporting and disclosure became among the basics of a healthy CG system. In the MENA region, not all firms have the required infrastructure of this system while Utama (2012) reveals that SMEs have a lower level of disclosure. In Egypt, Hassan's (2013) study links the failure of a clear information disclosure by the enterprises to the absence and the non-sufficient regulatory framework in the country. Also, the reason behind this failure goes back to socio-economic issues as Samaha et al. (2012) predicted that it will take the Egyptian firms some time to envision the long-term benefits of high levels of CG disclosure. As a result, it is obvious that effective CG needs both internal and external supporting factors.

In their study to explore CG practices in the MENA region while focusing on Saudi Arabia and Egypt, Piesse et al. (2012) found a significantly low level of disclosure and transparency compared to Anglo-American countries. The study also revealed a concentered management and control in the hands of family members who dominate the shareholders. Nheri (2014) studied 75 newly privatized firms across Egypt, Tunisia and Morocco to conclude that the choice of privatization increases the effectiveness of the CG method used, resulting in higher levels of output and efficiency. While in Lebanon, the reality is not any better, and the level of information disclosure remains voluntarily to a great extent. El-Kassar et al. (2014) detected a need to improve CG structures in developing countries in general and Lebanon in particular. Yet few non-governmental organizations such as the Lebanese Transparency Association established specific guidelines and principles for financial disclosure and reporting for SMEs and FOEs (Koldertsova, 2011). Chahine and Safieddine (2008) show that the banking sector in Lebanon is the most active sector in CG mechanism due to the weak external financial monitoring, and thus obliging the banks to put more efforts and be involved in building up CG standards, since they are the primary financing source for most businesses. Consequently, SMEs and FOEs in Lebanon did not yet realize the potential advantages of CG practices in general and transparency of financial data in specific.

\subsection{Analysis of ownership structure and control privileges}

With FOEs and SMEs dominating the business enterprises in the Lebanon and Egypt, CG practices became more challenged given the highly centralized control power. Khalil et al. (2015) explained that as the quality of available protection for shareholders varies, the financial 
contracting varies too. Firms in developing nations, such as MENA countries, believe that it is non-beneficial to spend time on CG and it is better to leave the rights of the minority shareholders be identified at a country level instead of at a company level (Doidge et al., 2007). Therefore, in order to protect investors, an efficient CG system is essential to be applied.

In Lebanon, research about CG is scarce, lacking general guidelines and rules; businesses are inclined to establish their own set of policies. Since families own the majority of the voting shares, and given that the Lebanese commercial law allows shares to be issued with unequal voting power, families attain further power and control over business decisions (Salloum et al., 2013), whereas in Egypt, the law does not differentiate the roles of a chairperson and a managing director, and the Egyptian Institute of Directors was among the first to launch CG systems and codes for SMEs in 2006 (Gamal El Din, 2009).

The progress of CSR in the region does not lie only on the enterprises and their employees alone, governments and non-profit organizations have taken some steps among the years.

In Dubai for examples, the regional institute for CG was established in 2006 in Dubai, to better advance CG reforms. Moreover, CSR awareness is being spread through networks like CSR Middle East, whose members are companies, agencies and organizations interested in communication social responsibility and corporate citizenship initiatives in the Middle East.

When analyzed, the Middle East region, compared to the developed world, was late in adopting CSR as a whole and practices that are concerned with this realm. However, adoption and awareness improved significantly over the past decade with stakeholders realizing the importance of CSR. With that in mind, organizations in the Middle East can no longer take CSR as a light matter, since the well-being of the society and their professional reputation are directly cultivated through their social actions and thus their business decisions.

With the presence of high corruption indices and political instability in the MENA region in general, as much as CG is highly demanded in these days, its application will be further postponed until economies and situation settles down a bit.

\subsection{Structure of board of directors}

The board of directors performs both a monitoring and advisory role. While monitoring, the board is responsible for determining standards, ideals and principles, along with ensuring that the referred to are set in place. In Lebanon, the concept of separating between ownership and control is not realized (Salloum et al., 2013). In most cases, the board members hold the same family name as the owners without forgetting the possibility of the CEO duality. Ehikioya (2009) studied CG structure and firm performance in developing countries to find that CEO duality and the existence of more than one family member in the board have an adverse impact on the firm's performance. In developed countries, the ownership structure is dispersed while in developing ones it is concentrated (Ehikioya, 2009). This is significantly true in Lebanese and Egyptian SMEs and FOEs.

Ahmed and Hamdan (2015) conducted a study on Bahraini listed firms and indicated that the return on assets and the return on equity are positively influenced by CG mechanisms. It goes on to discuss that promoting a good governance system attracts investment capital, reduces risk and increases the firm's performance. Moreover, at the level of ownership structure, the agency theory approach can never be dismissed. Bonazzi and Islam (2007) considered that the monitoring of CEO by the board will improve the CEO's performance and steer the firm away from probable conflict of interests and agency problems.

\subsection{Audit committee}

According to Mahmood (2008), any code of CG must at least include the following fundamental keys: board of directors, corporate financial reporting, independent external audit and internal audit. Ghafran and O'Sullivan (2013) stated that financial statements attain a higher quality, when audit committees are more independent and reveal good 
expertise in finance/accounting. The study also showed that the existence of this committee positively impacts the firm's performance. In Korea, Choi et al. (2014) found that, in general, the stock price of a company increases with audit committee appointments. A Malaysian study by Kallamu (2016) examined the impact on audit committee attributes and firm performance as a result of the code of CG being revised, to find that these attributes were significantly improved.

\subsection{Business ethics}

Ethics are the rules and principles that specify how an individual or individuals within an entity should to behave. Ethical issues are important to individuals and professionals in everyday life whether in businesses, academia or elsewhere (Gbadamosi, 2004). CG must be examined from an ethical and moral stance. Thus, business ethics must be strongly enforced in a world where greed and profit seeking blind out the minds oftentimes. Although large firms have established and comply by strong ethical standards (Mahmood, 2008), SMEs in developing countries are still halfway in understanding the importance and the impact of business ethics. Rossouw (2005) considers that the way a "company treats its stakeholders reflects its ethical standards." Given the fact that good CG is based on a number of fundamental ethical values, Rossouw (2005) listed the four top values of good CG: transparency, accountability, responsibility and probity. In addition to that, the board of directors has moral and ethical obligations toward its stakeholders such as enduring the rights of shareholders (majority and minority), as well as the rights of employees and their safety (Rossouw, 2005). And since ethical practices are concerned with the general welfare of all stakeholders, equally and fairly, the presence and the practice of good CG will further enhance these ethical behaviors and increase the weight of their associated results and benefits. On the other hand, ethics are not only measured at the level of actions in fact, they start from the decision-making point.

In MENA countries for instance, the Corruption Perceptions Index of 2014 ranked Lebanon and Egypt at 136 and 94, respectively, out of 175, the most corrupt is ranked 175. This indicator tells a lot about business ethics in these two countries revealing an urgent need in ethics restoration while conducting business. Because at the end of the day, firms are nothing but a group of people planning and implementing decisions, the ethics of these people are translated into the firm's ethics. As a result, in order to have high business ethics, strong personal ethics is needed parallel to effective CG system, which ensures the enforcement of rules, increases transparency and minimizes the chances of fraud.

\subsection{CSR}

Kim et al. (2014) believe that firms are recently gradually including CSR in their strategies in order to satisfy their stakeholders and gain a positive image in the market. While there are always questionable motives behind CSR engagement by firms, it seems that regardless of these motives, firms and their stakeholders are more realizing the socially responsible role and the contribution that a firm must undertake and is expected to do by its community.

For example, the state of Qatar has placed major emphasis on CSR in order to meet the goals set by its Qatar National Vision 2030, defined as the road to sustainability based on four major elements: human; economic; environmental; and social development (Corporate Social Responsibility Report, 2014).

Building on this, the country is offering some valid opportunities to elevate the CSR dimensional construct in its realm. For instance, Doha Bank are pioneers in raising awareness on environmental changes and climate effect issues in Qatar; the banks envisions itself leading the way in "Green banking" by encouraging green accounts, "Go Green" credit cards, paperless banking, etc. 
Alongside this, products the Bank has become a leading entity in Qatar and the Middle East for environmental advocacy through numerous CSR initiatives including Eco-schooling and Green Run.

However, in the developing countries, CSR activities are not enough advanced. In Lebanon, CSR is limited to specific sectors and multinational corporations, and there is no tangible differentiation in the approaches adopted. Deloitte Middle East, for example, are MENA CSR pioneers committed to driving societal change for the better through initiatives that focus on corporate responsibility and on sustainability. Unlike others, the focus of Deloitte is on education and skills for underserved youth, they also are committed to humanitarian causes and to creating a sustainable future.

Through philanthropy, Lebanese banks such as Bank Audi, Byblos Bank and Bank of Beirut started their CSR activities while other companies have declared their ethical codes of conduct. Also, the American Lebanese Chamber of Commerce (AmCham Lebanon, 2009) started the Better Business Group aiming to share business principles between managers and decision makers (p. 9). In Egypt, a study by El Kayaly (2014) showed that Egyptian firms lack any CSR direction and implement CSR practices for marketing purposes only, while also some private banks and companies started their CSR activities including QNB Al Ahli Bank and Procter and Gamble Egypt. In both countries, CSR is executed reactively more than proactively, associated with weak and sometimes full absence of vision and planning. Therefore, high potential for firms in the MENA region is present, if they tend to invest wisely in CSR benefiting themselves, communities and stakeholders rather than merely providing products and services.

On the other hand, as the concept of CSR evolved to incorporate responsibilities beyond economic ones, building and maintaining an ethical identity for the business became essential, especially with the increasing awareness of customers and general well-being of communities. This ethical responsibility along with other societal, legal and environmental obligations have widened and diversified the extent of which a firm can play its ethical role and thus be an active player at a CSR level. Therefore, in a developing country context, business entities still have wide and diversified opportunities to utilize their full CSR potential and be more innovative in their approaches. Moreover, Sacconi (2012) considered CSR a model of CG with a focus on stakeholders other than shareholders. According to him, the "constitutive" view sees CSR as "the governance model on the basis of which a company pursues [...] the joint interest and mutual advantage of all its relevant corporate stakeholders" (Sacconi, 2012, p. 13). Taking it further, Jo and Harjoto (2012) findings proved that CG increases CSR while CSR positively affected the financial performance of the company. As a result, it is no surprise that good CG practices directly influence the relationship between business ethics and CSR, given that the last two reflect the strength and quality of the CG structure enacted in the firm.

\section{Hypotheses development}

Scandals and failures in the corporate world have impacted how companies being perceived as profit-maximizing and self-centered entities. Nowadays, companies are changing their image to be viewed as citizens paying attention to accountability, good governance, trust, ethical and social, and environmental issues. These changes in focus have attracted the interest of both academicians and practitioners to examine the role that corporate ethics, CG and CSR play in achieving organizational success. Recent research studies have examined corporate ethical practices, CG and CSR independently, as well as the association among these factors (Hojo on direction of association between CG and CSR). Nevertheless, holistic model examining these relationships may potentially impact corporate success especially in a region such as the MENA region. Organizations in this region have failed to attract international investors due to the track record. 
Drawing on a theoretical framework comprising the stakeholder theory (Freeman, 1984) and agency theory, these relationships are analyzed to derive a conceptual model to holistically examine the relationships among CE, CG and CSR. The proposed relationships are empirically tested using survey data targeting corporations operating in two MENA region countries, Egypt and Lebanon.

\subsection{Stakeholder theory}

Originally detailed by R. Edward Freeman, the stakeholder theory begins by addressing values and morals for managing an organization. In brief, the theory identifies the groups that compromise an organization's stakeholders and designates tailored approaches that management can give due regard to the interests of the mentioned groups, i.e. addressing who or what really counts. Freeman's proposed study traced a path that buoys up the consideration of new stakeholders, beyond the traditional pool, including employees, clients and vendors, signifying in turn novel methods of managerial understandings. With this in mind, organization are expected to indulge in more responsible management techniques extended to meet the interests of all stakeholders, including the silent ones such as local communities and the environment; hence, stakeholder theory proposed a refreshed way to think about organizational responsibilities that extend beyond profit maximization.

In comparison to the traditional understanding, the shareholder outlook, only the owners or stockholders of an organization are important, and the enterprise has a binding duty to place their needs first along with increasing their benefits. Stakeholder theory, on the other hand, debates that other parties are included such as employees, clients, vendors, societies, governmental entities, associations, unions, etc. Moreover, Freeman explains that managers need to comprehend the rationale or organizational process put in place to deal with the respective stakeholders. They are impelled at an individual level to exert discretion toward socially responsible results within every domain of CSR (Wood, 1991).

Adding on, the stakeholder theory poses two lines of view: instrumental or normative. The instrumental theory assumes that an organization is an instrument for capital and wealth formation, which utilizes CSR as a tool to promote economic objectives, whereas the normative theory defines moral commitments toward stakeholders, concentrating on ethical requirements that build the relationship between business and society (Jamali, 2008).

\subsection{Agency theory}

The agency theory (Eisenhardt, 1989) defines the relationship between one individual (agent) who acts on behalf of another (principal) in an organization, where he or she is supposed to progress the goals of the latter. The principal-agent issue is highlighted when the agent is hired to perform tasks or services with a decision-making authority but the actions of the agent do not meet the goals of the principal.

The theory entails means of resolving conflicts present in agency relations owed to these unbalanced goals or diverse attitudes toward risk. It targets resolutions for two problems that may arise in an agency relationship. The first scenario ascends when wishes or targets of an agent and principal collide. The second scenario is the issue of risk sharing that occurs when the agent and principal have dissimilar approaches concerning risk; each may have a may pose a targeted action different from the other due to divergent risk inclinations. An utmost common agency relationship happens amongst shareholders (principal) and company executives (agents).

The management of agency relationship plays vital role in both CG and CSR, as they both can be viewed from a principal-agent relationship perspective, reflecting how crucial it is to explain paused relations between various groups and the choices made for the right strategies to manage the agency problems risen (Germanova, 2008). For example, based on the agency theory, Barnea and Rubin (2010) suggest that if CSR initiatives do not exploit 
organizational value, such initiatives waste resources and a potentially value-destroying proposition. Barnea and Rubin (2010) observe the relationship between firms' CSR ratings and their ownership/capital structures, and argue that insiders tend to overinvest in CSR. Effective CG prevents overinvestment, thus predicting an inverse relationship between CSR and CG. Therefore, due to the rising significance of the stakeholder and agency theory in CSR literature, we examine the causal relations and impacts present between $\mathrm{CG}, \mathrm{CE}$ and CSR.

Good CG is based on a number of fundamental ethical standards that include transparency, accountability, responsibility and probity. In addition, the board of directors and the owners of an entity have moral and ethical obligations toward their stakeholders, the presence of CG will further dwell upon these behaviors and increase actions enhancing the decision-making process. Trong (2012) noted that many interrelate CG with ethics and morals. Numerous studies have examined the relationship between ethical practices on CG and identified the need for an internationally acceptable guidelines and ethical behaviors upon building up a CG system. El-Kassar et al. (2015) studied the effects of ethical practices on CG in developing countries. Mahmood (2008) examined the challenges of CG and business ethics for SMEs in developing countries. Ethical practices have also been linked to CSR (Fülöp et al., 2000; El-Kassar, 2017). Accordingly, the following hypotheses are posited:

H1. Ethical practices have a positive impact on $\mathrm{CG}$.

H2. Ethical practices have a positive impact on CSR.

In order to satisfy stakeholders and gain a positive image, firms adopted CSR in their agenda and embedded it into their strategies. CSR has been shown to support SMEs (El Kayaly, 2014), drive innovation (Kim et al., 2014) and to have positive effects on employee-company identification and organizational citizenship behavior (El-Kassar et al., 2017). In fact, the concept of CSR developed beyond economic responsibilities as building and maintaining an ethical identity became prominent, especially when stakeholder became more interested in the overall well-being of the society. Thus, CSR has been considered as a model of CG (Jo and Harjoto, 2012; Sacconi, 2012; Dahawy, 2008) with a focus on stakeholders rather than shareholders.

Building an ethical identity for businesses became essential, especially with the increasing awareness of customers and general well-being of communities. This ethical responsibility along with other societal, legal and environmental obligations have widened the extent where a firm can play its ethical role and thus be an active player at a CSR level. A good CG practice directly influences the relationship between business ethics and CSR, given that the two reflect the strength and quality of the CG structure enacted by the firm. Hence, we posit the following hypotheses:

H3. CG has a positive impact on CSR.

H4. CG mediates the relationship between ethics and CSR.

Figure 1 depicts the theorized relationships between ethics and CSR, with CG being a mediator.

\section{Methodology}

The proposed model depicted in Figure 1 and the established hypotheses are tested, and the model goodness-of-fit is reported. The methodology and the results are presented and discussed below.

\subsection{Design and data collection}

The target population of the study is SMEs (non-public) in developing countries in the MENA region. The data for this study were collected through a questionnaire distributed in ethics, CG and

CSR in MENA countries 
$\mathrm{MD}$

56,1

\section{2}

Figure 1.

Conceptual framework

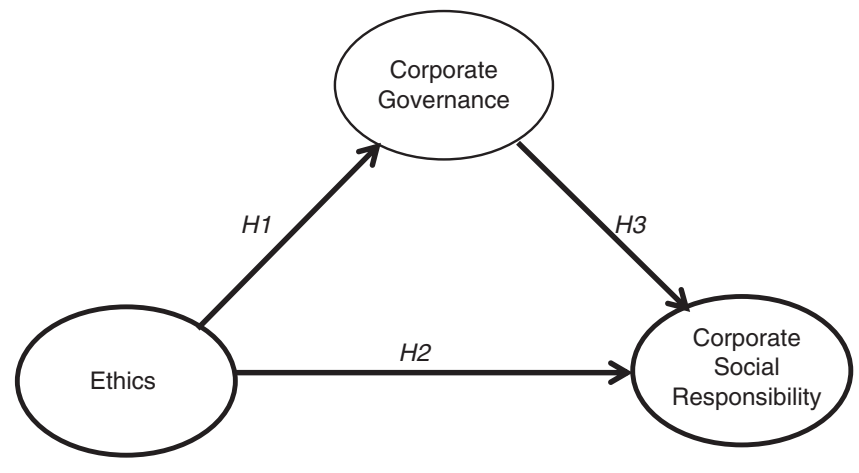

Lebanon and Egypt to employees working the SMEs via e-mail. SMEs participated in this study were selected through personal contacts. The participating employees were chosen based on their knowledge on CG matter. The questionnaire was supplemented with a cover letter stating the objectives of the study, the confidentiality of their responses, and the fact that the participation is voluntary. It is worth noting that it is common that respondents from family business and SMEs are very unlikely to report their financial and nonfinancial information often because the firms are not publicly traded (Kellermanns et al., 2012).

The selection of Lebanon and Egypt is due to the fact that countries such as UAE and KSA were excluded as they are more developed and similar to western countries. Prior studies about western countries are abundant. The remaining MENA region countries do share similar cultural and economic characteristics as Lebanon and Egypt. Being one of the largest countries in the MENA region, the choice of Egypt is an excellent representation of the region. Also, having a small country like Lebanon in the sample reflects the representation of the other small counties in the region and further justify the of sample size. When the results from the two countries were compared, no significant differences were found between the two countries. Thus, the analysis is conducted based on the entire sample.

Of the 400 questionnaires distributed, 178 responded to the survey - a response rate of approximately 44.5 percent - of which 172 were deemed usable. A summary of the sample demographics is given in Table I.

The questionnaire consisted of seven parts, including questions related to demographics, the four components of CG (transparency, audit committee, board of directors and ownership structure), corporate ethics and CSR.

Items related to CG and CSR (Tables III-VII) were extracted from Dahawy (2008), while items related to ethical practices (Table II) were based on El-Kassar et al. (2015).

\section{Country}

Company size

Size of board of directors

Respondent's years of experience

Table I. Sample demographics

\author{
Lebanon: $49.4 \%$ \\ Egypt: $50.6 \%$ \\ Small enterprise: $43 \%$ \\ Medium enterprise: $57 \%$ \\ 1-4: $17.4 \%$ \\ 5-10: $43 \%$ \\ Other: $39.6 \%$ \\ Less than 10: $50 \%$ \\ 10 or more: $50 \%$ \\ CA/CPA/CIA: $54.7 \%$ \\ Other: $45.3 \%$
}


ETH1 Activities of the board, management and employees are guided by the moral code of good conduct

ETH2 Employees are pushed to be truthful in their reporting and their practices

ETH3 Reporting accurate and reliable financial statements is ensured

ETH4 Responsibility toward the organizations and the community is encouraged

ETH5 Building and establishing employees' credibility is ensured

ETH6 The interests of all stakeholders are considered in decision making

ETH7 A whistleblower program protection exists

ETH8 The organization's members share a common set of beliefs, values and practices

ETH9 Employees are treated fairly and equally, with no one employee treated with favoritism

ETH10 Fundamental values in culture such as integrity and dependability are integrated

ETH11 The interest of the organization is prioritized over personal advantages

ETH12 The interest of stakeholders is prioritized over personal advantages

ETH13 Following moral norms and values by managers and employees are warranted

Note: ETH, ethics

Table II

Ethics and its role in corporate governance

The four components of CG (transparency, audit committee, board of directors and ownership structure), corporate ethics and CSR were all measured using a five-point Likert scale (ranging from Strongly Agree to Strongly Disagree).

To address the research question of how ethics impacts the various categories of CG, a score for each of these categories is constructed by averaging the responses of the items constituting the categories. In addition to these five scores, an overall CG score and a score for ethics are also constructed.

These scores will be denoted by:

- TRSS for transparency of financial data score.

- OWNS for analysis of ownership structure and control privileges score.

- BRDS for structure of board of directors and management score.

- CSRS for corporate social responsibility score.

- ADTS for analysis of auditing committee and elements score.

- GCS for corporate governance score.

- ETHS for ethics score.

These scores, along with the demographics variables and the individual items, will be used to conduct the statistical analysis.

\subsection{Measurement instrument and construct measures}

The four categories of CG are measured using 46 items (Tables III-VII). As the CG construct in this case is presented as a higher-order multidimensional construct, the parceling method to

\begin{tabular}{ll}
\hline TRSP1 & Financial results \\
TRSP2 & Objectives of the company \\
TRSP3 & Accounting evaluations \\
TRSP4 & Related party transactions: elements and nature \\
TRSP5 & Related party transactions: practices and disclosure (under control) \\
TRSP6 & Board's duties and financial communications \\
TRSP7 & Extraordinary transactions regulations \\
TRSP8 & Alternative accounting decisions: impact and analysis \\
TRSP9 & The process for decision making and approval of transactions with related parties \\
Note: TRSP, transparency of financial data
\end{tabular}

Table III.

Transparency of financial data 
transform this construct into a first-order latent variable consisting of the four dimensions

\subsection{Data analysis}

The structural relationships were analyzed using partial least squares structural equation modeling (PLS-SEM) in SmartPLS 3.0. This study used PLS-SEM because of the relatively

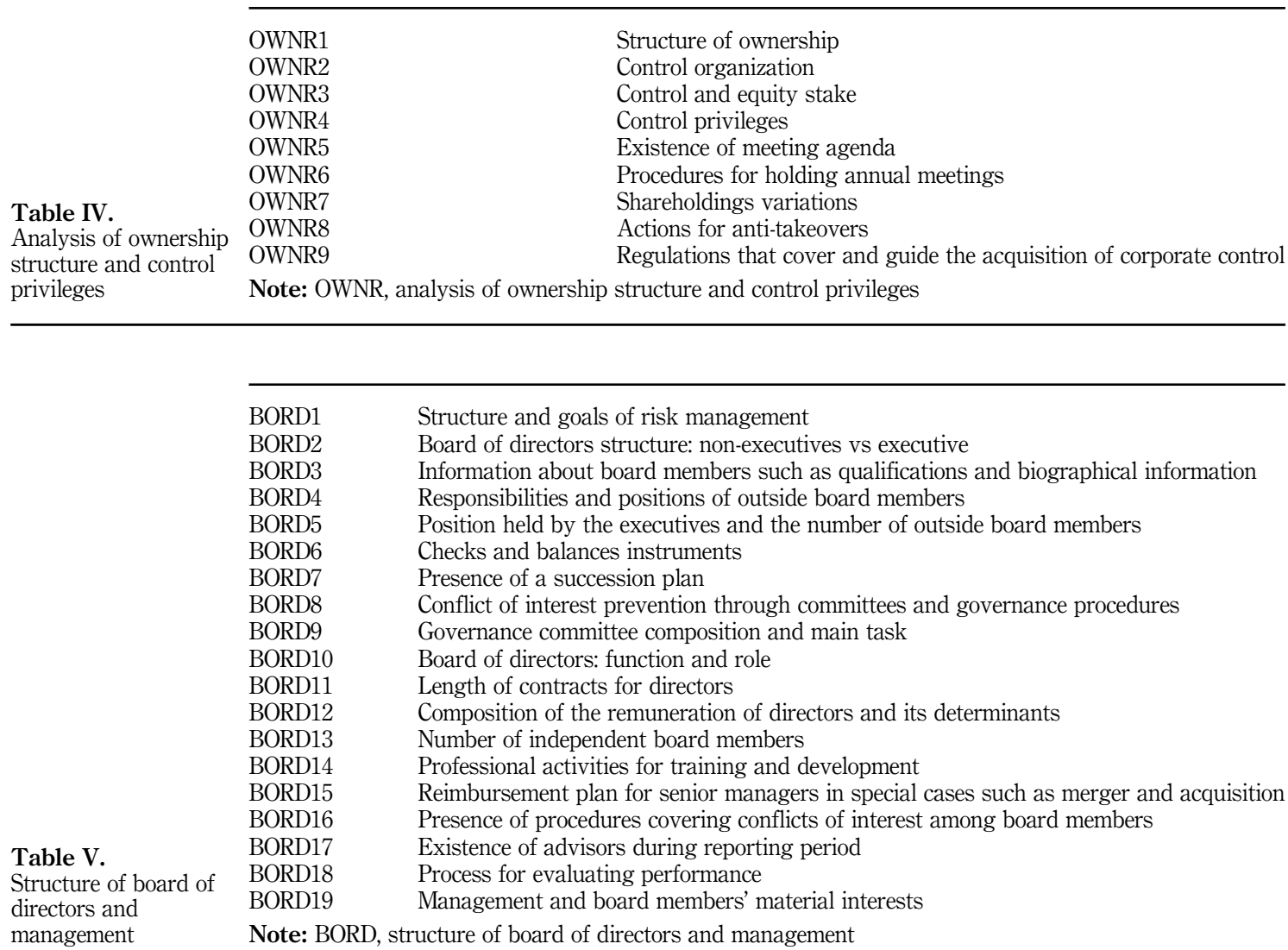

$\begin{array}{ll}\text { ADTC1 } & \text { Procedures governing collaboration with external auditors } \\ \text { ADTC2 } & \text { Procedures and responsibilities for appointing internal auditors } \\ \text { ADTC3 } & \text { Reliability of external auditors and board's confidence } \\ \text { ADTC4 } & \text { Procedures governing collaboration with internal auditors } \\ \text { ADTC5 } & \text { Decision-making procedure for appointing external auditors } \\ \text { ADTC6 } & \text { Internal control systems } \\ \text { ADTC7 } & \text { Period of auditor contracts } \\ \text { ADTC8 } & \text { Audit partner rotation process } \\ \text { ADTC9 } & \text { The remuneration of auditors and involvement in non-audit work }\end{array}$

Note: ADTC, analysis of auditing committee and elements 
small sample size. The structural model was analyzed by first validating the outer model and second, by fitting the inner model. Validating the outer model was accomplished by determining the convergent and discriminant validity and reliability for the first-order latent constructs (Wetzels et al., 2009). Fitting the inner model was accomplished primarily through path analysis with latent variables.

For CG, confirmatory factor analysis was conducted on each of the four CG components: audit committee, board of directors, ownership structure and transparency. The 19 items of the board of directors' component of CG were factor analyzed resulting in three factors: BRDF1, BRDF2 and BRDF3. The first factor, BRDF1, included items BRD2, BRD3, BRD4 and BRD5 with extraction sums of squared loadings of 73.6 percent. The second factor, BRDF2, included items BRD6, BRD7, BRD8, BRD9, BRD14, BRD16, BRD17, BRD18 and BRD19 with extraction sums of squared loadings of 60.2 percent. The third factor, BRDF3, included items BRD10, BRD11, BRD12, BRD13 and BRD15 with extraction sums of squared loadings of 60.41 percent. In each case, a score was calculated to represent the corresponding factor. Using these scores, confirmatory factor analysis was applied to show that the scores can be combined to measure the overall board effectiveness. The component matrix showed loadings of $0.840,0.917$ and 0.874 for the three factors. In addition, the extraction sums of squared loadings were 77.005 percent.

The nine items of the audit committee component of $\mathrm{CG}$ were factor analyzed resulting in two factors: ADTCF1 and ADTCF2. The first factor, ADTCF1, included items ADTC1, ADTC2, ADTC3, ADTC4, ADTC5 and ADTC6 with extraction sums of squared loadings of 45.42 percent. The second factor, ADTCF2, included items ADTC7, ADTC8 and ADTC9 with extraction sums of squared loadings of 75.154 percent. In each case, a score was calculated to represent the corresponding factor. In addition, confirmatory factor analysis showed that these scores can be combined to measure the overall effectiveness of the audit committee. The component matrix showed loadings of 0.749 for ADTCF1 and 0.663 for ADTCF2. In this case, the extraction sums of squared loadings were 50 percent.

The nine items of transparency component of CG were loaded into one single factor, showing extraction sums of squared loadings of 66.376 percent; a single factor TRSP was obtained. Similarly, the six items of the ownership structure component of CG resulted in one single factor yielding a single score (OWNR) with extraction sums of squared loadings of 68.56 percent. The resulting four scores (BORD, ADTC, OWNR and TRSP) were used to transform the CG construct into a first-order latent variable.

Confirmatory factor analysis was also conducted for ethics. The 13 items measuring ethical practices were factor analyzed resulting in three factors: ETHF1, ETHF2 and ETHF3. The first factor, ETHF1, included items ETH1, ETH2, ETH3, ETH4 and ETH5 with extraction sums of squared loadings of 71.721 percent. The second factor, ETHF2 included items ETH6, ETH7, ETH8, ETH9 and ETH10 with extraction sums of squared loadings of 63.358 percent. The third factor, ETHF3, included items ETH11, ETH12 and ETH13 with extraction sums of squared loadings of 78.703 percent. Then a score for each factor was calculated. Factor analysis showed that the scores can be combined to measure the level of ethical practices. The component matrix showed loadings of $0.784,0.855$ and 0.847 for the three factors. In addition, the extraction sums of squared loadings were 68.742 percent. The three factors were used to measure the ethical practice as a first-order latent variable. Finally the three items of CSR were used to measure CSR engagement.

CSR2

CSR3

Note: CSR, corporate social responsibility
Corporate ethics, CG and CSR in MENA countries

285
Table VII.

Corporate social responsibility 
$\mathrm{MD}$

56,1

286

Table VIII.

Construct reliability

\subsection{Structural model results}

The measures of reliability and validity are depicted in Table VIII. The results show that the model is reliable as the values of Cronbach's $\alpha$ and composite reliability were greater than the value of 0.7. In addition, the value of the average variance extracted for each variable was well above 0.5 threshold. This implies that more than 50 percent of the variance was explained by the constructs. This proves that the model presented is of high reliability and consists of reflective factors.

The validity of the scales used in this study was demonstrated as the diagonal entries that are larger than the values appearing in their respective rows or columns, shown in Table IX.

The path analysis results shown in Figure 2 indicate that all path coefficients are positive. The bootstrap test was conducted to determine the significance of the path coefficients. The direct effect results, shown in Table X, indicate that $H 1$ was supported. Hence, significant evidence was found to conclude that ethical practices have a positive impact on CG (path coefficient $=0.625$, $p$-value: 0.000 ). The results showed that $H 2$ was not supported indicating that CSR is not directly impacted by ethical practices (path coefficient $=0.223, p$-value $=0.105$ ). As for $H 3$ the results provided significant evidence that CG has a positive impact on CSR (path coefficient $=0.383$, $p$-value $=0.000$ ).

\begin{tabular}{lcccc}
\hline & Cronbach's $\alpha$ & $\rho_{-} \mathrm{A}$ & Composite reliability & Average variance extracted (AVE) \\
\hline CG & 0.817 & 0.834 & 0.878 & 0.643 \\
CSR & 0.907 & 0.911 & 0.942 & 0.844 \\
ETHICS & 0.772 & 0.778 & 0.868 & 0.687 \\
\hline
\end{tabular}

\begin{tabular}{lccc}
\hline & CG & CSR & Ethics \\
\hline CG & 0.802 & & \\
CSR & 0.529 & 0.919 & \\
Ethics & 0.652 & 0.473 & 0.829
\end{tabular}

Table IX.

Discriminant validity of variables construct

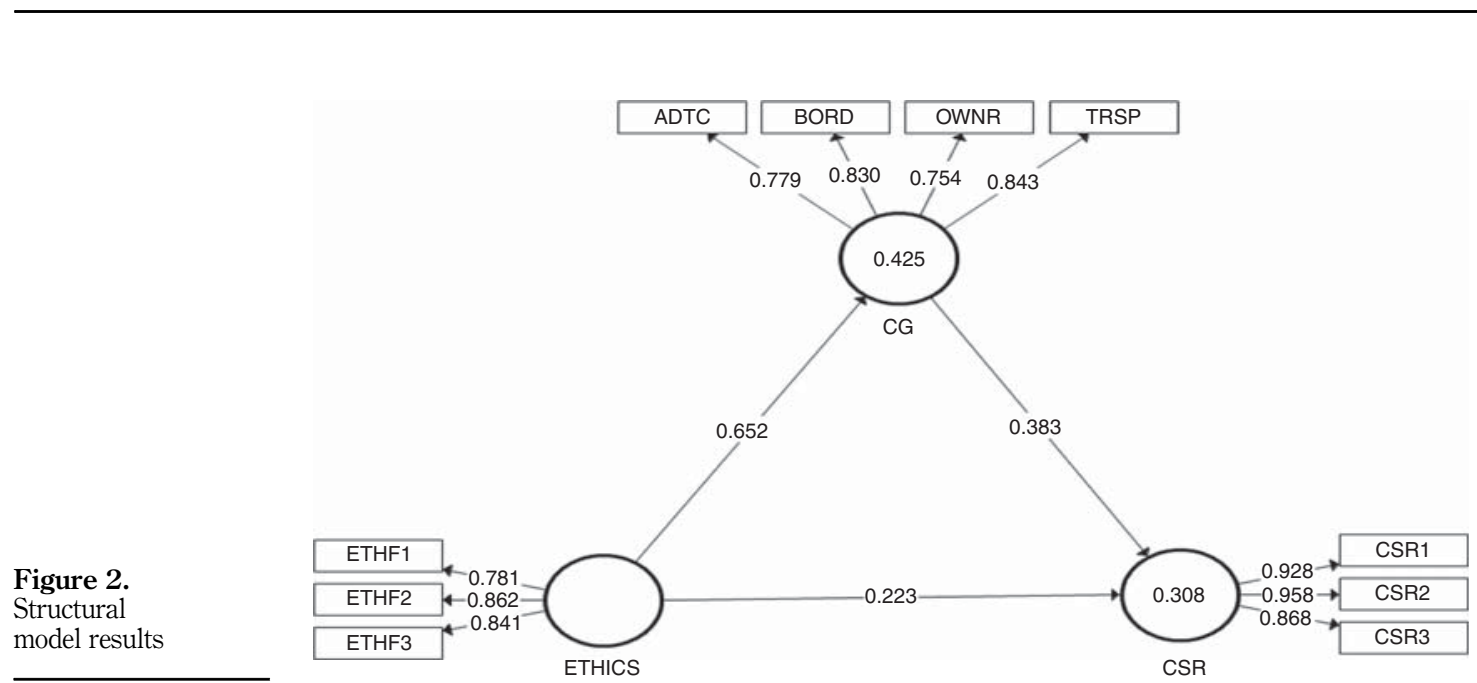


Examining the mediating effects of $\mathrm{CG}$ on the relationship between ethical practices and CSR, the indirect results showed a significant indirect effect (path coefficient $=0.250$, $p$-value $=0.001$ ) supporting H4. This along with the fact that the direct effect did not show a direct significant impact between ethics and CSR indicate that CG fully mediates the relationship between ethics and CSR.

\section{Limitations and future research}

The sample size was relatively small while a larger one may expose a more accurate significance. Although it was valid to look at SMEs as they are expected to have a lower CG mechanism than larger companies, yet those companies (large enterprises) are expected to have higher social responsibility engagement. Hence, future research can compare the differences in CG and CSR levels between SMEs and large companies. Since the study did not support the direct relationship between ethics and CSR, future studies can examine mediators other than CG (i.e. culture) on this relationship.

\section{Conclusion}

As stated, implementing CG may not be as easy as it appears, especially when it comes to the corporate realm, but researchers have agreed on the importance of CG in enforcing CSR and ethical principles with in an entity.

Business ethics are the rules and principles that define how an individual or a group of individuals within a firm behaves; ethical issues are vital for professionals in their everyday lives; for this reason business ethics must be strongly enforced in the field of profit-seeking establishments. The first relationship studied lies between ethics and CG; good CG is based on a number of fundamental ethical values, these include transparency, accountability, responsibility and probity. In addition, the board of directors and the owners of an entity have moral and ethical obligations toward their stakeholders, the presence of $\mathrm{CG}$ will further dwell upon these behaviors and increase actions enhancing the decision-making process.

The study moves on to discuss the relationship between CG and CSR. In order to satisfy stakeholders and gain a positive image, firms have adopted CSR in their agenda and embedded it into their strategies; the concept of CSR developed beyond economic responsibilities as building and maintaining an ethical identity became prominent, especially when stakeholder became more interested in the overall well-being of the society. Thus, CSR has been considered as a model of CG with a focus on stakeholders rather than shareholders.

Moreover, a good CG practice directly influences the relationship between business ethics and CSR, given that the two reflect the strength and quality of the CG structure enacted by the firm.

A conceptual model was developed to tackle this issue and data were collected through research and questionnaires from SMEs in MENA countries. The results were then analyzed

\begin{tabular}{|c|c|c|c|c|c|c|c|c|}
\hline & $\begin{array}{l}\text { Original sample } \\
\text { (O) }\end{array}$ & $\begin{array}{l}\text { Sample mean } \\
\text { (M) }\end{array}$ & $\mathrm{SD}$ & $\begin{array}{c}t \text {-Statistics } \\
(\mid \mathrm{O} / \mathrm{SD})\end{array}$ & $\begin{array}{l}\text { Lower } \\
\text { limit }\end{array}$ & $\begin{array}{l}\text { Upper } \\
\text { limit }\end{array}$ & $p$-Values & \\
\hline \multicolumn{9}{|c|}{ Path coefficients: direct effects } \\
\hline $\mathrm{CG} \rightarrow \mathrm{CSR}$ & 0.383 & 0.385 & 0.100 & 3.851 & 0.181 & 0.583 & 0.000 & \multirow{5}{*}{$\begin{array}{r}\text { Table X. } \\
p \text {-Values of structural } \\
\text { model results }- \text { direct } \\
\text { and indirect effects }\end{array}$} \\
\hline ETHICS $\rightarrow$ CG & 0.652 & 0.655 & 0.047 & 13.735 & 0.556 & 0.740 & 0.000 & \\
\hline ETHICS $\rightarrow$ CSR & 0.223 & 0.220 & 0.137 & 1.626 & -0.085 & 0.467 & 0.105 & \\
\hline \multicolumn{8}{|c|}{ Path coefficients: indirect effects } & \\
\hline ETHICS $\rightarrow$ CSR & 0.250 & 0.253 & 0.072 & 3.475 & 0.013 & 0.399 & 0.001 & \\
\hline
\end{tabular}

Corporate ethics, CG and CSR in MENA countries

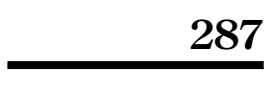


using SEM to indicate that ethical practices have positive impact on CG, and CG has a positive impact on CSR. Also, the results supported the mediating effect of CG on the relationship between ethics and CSR.

Jo and Harjoto (2012) found that CG causes CSR, while an inverse relationship does not exist. Consequently, more emphasis on $\mathrm{CG}$ is taking place along with the increasing awareness about CSR. Moreover, ethics will always remain the foundation in conducting any business; thus, exploring its impact on both CG and CSR is valuable.

\section{References}

Aguilera, R., Florackis, C. and Kim, H. (2016), "Advancing the corporate governance research agenda", Corporate Governance: An International Review, Vol. 24 No. 3, pp. 172-180.

Ahmed, E. and Hamdan, A. (2015), "The impact of corporate governance on firm performance: evidence from Bahrain Bourse", International Management Review, Vol. 11 No. 2, pp. 21-37.

Aluja, A. and Blanch, A. (2004), "Depressive mood and social maladjustment: differential effects on academic achievement”, European Journal of Psychology of Education, Vol. 19 No. 2, pp. 121-131.

American Lebanese Chamber of Commerce (AmCham Lebanon) (2009), Online newsletter, available at: www.amcham.org.lb

Bagozzi, R.P. and Edwards, J.R. (1998), "A general approach for representing constructs in organizational research”, Organizational Research Methods, Vol. 1 No. 1, pp. 45-87.

Barnea, A. and Rubin, A. (2010), "Corporate social responsibility as a conflict between shareholders", Journal of Business Ethics, Vol. 97 No. 1, pp. 71-86.

Ben Barka, H. and Dardour, A. (2015), "Investigating the relationship between director's profile, board interlocks and corporate social responsibility", Management Decision., Vol. 53 No. 3, pp. 553-570.

Bocquet, R., Le Bas, C., Mothe, C. and Poussing, N. (2013), "Are firms with different CSR profiles equally innovative? Empirical analysis with survey data", European Management Journal, Vol. 31 No. 6, pp. $642-654$.

Bonazzi, L. and Islam, S.M. (2007), "Agency theory and corporate governance: a study of the effectiveness of board in their monitoring of the CEO", Journal of Modelling in Management, Vol. 2 No. 1, pp. 7-23.

Cadbury, A. (1992), "Report of the committee on the financial aspects of corporate governance". Gee, p. 1.

Cansiz, M. (2008), “Turkiye'de KOBI'ler ve KOSGEB”, Uzmanlık Tezi, DPT, Ankara.

Cantista, I. and Tylecote, A. (2008), "Industrial innovation, corporate governance and supplier-customer relationships", Journal of Manufacturing Technology Management, Vol. 19 No. 5, pp. 576-590.

Chahine, S. and Safieddine, A. (2008), "Corporate governance and the external monitoring of banks in Lebanon", Corporate Governance: The International Journal of Business in Society, Vol. 8 No. 3, pp. 258-270.

Choi, Y.K., Han, S.H. and Lee, S. (2014), "Audit committees, corporate governance, and shareholder wealth: evidence from Korea", Journal of Accounting and Public Policy, Vol. 33 No. 5, pp. 470-489.

Claessens, S. and Yurtoglu, B.B. (2013), "Corporate governance in emerging markets: a survey", Emerging Markets Review, Vol. 15 No. 1, pp. 1-33.

Coffman, D.L. and MacCallum, R.C. (2005), "Using parcels to convert path analysis models into latent variable models”, Multivariate Behavioral Research, Vol. 40 No. 2, pp. 235-259.

Crowther, G. (2008), "Governance and sustainability: an investigation into the relationship between corporate governance and corporate sustainability", Management Decision, Vol. 46 No. 3, pp. 433-448.

Dahawy, K. (2008), "Developing nations and corporate governance: the story of Egypt", The International Financial Corporation (IF), The Global Corporate Governance Forum, 2009, available at: www.ifc.org/ifcext/cgf.nsf/AttachmentsByTitle/PaperKhaledDahawy/\$FILE/ Dahawy_Kahled4.Pdf (accessed September 24, 2016). 
Denis, D.K. and McConnell, J.J. (2003), "International corporate governance", Journal of Financial and Quantitative Analysis, Vol. 38 No. 1, pp. 1-36.

Doidge, C., Karolyi, G.A. and Stulz, R.M. (2007), "Why do countries matter so much for corporate governance?”, Journal of Financial Economics, Vol. 86 No. 1, pp. 1-39.

Ehikioya, B.I. (2009), “Corporate governance structure and firm performance in developing economies: evidence from Nigeria", Corporate Governance: The International Journal of Business in Society, Vol. 9 No. 3, pp. 231-243.

Eisenhardt, K.M. (1989), “Agency theory: an assessment and review”, Academy of Management Review, Vol. 14 No. 1, pp. 57-74.

El Kayaly, D. (2014), "Corporate social responsibility supporting SMEs: lessons learned from Egypt", Working Paper No. 2014/25, Maastricht School of Management, Netherlands.

El-Kassar, A.N., Elgammal, W. and Bayoud, M.M. (2014), "Effect of internal audit function on corporate governance quality: evidence from Lebanon", International Journal of Corporate Governance, Vol. 5 Nos 1/2, pp. 103-117.

El-Kassar, A.N., Messarra, L.C. and Elgammal, W. (2015), "Effects of ethical practices on corporate governance in developing countries: evidence from Lebanon and Egypt", Corporate Ownership \& Control, Vol. 12 No. 3, pp. 494-504.

El-Kassar, A.N., Yunis, M. and El-Khalil, R. (2017), "The mediating effects of employee-company identification on the relationship between ethics, corporate social responsibility, and organizational citizenship behavior", Journal of Promotion Management, Vol. 23 No. 3, pp. 1-18.

Freeman, R.E. (1984), Strategic Management: A Stakeholder Approach, Pitman/Ballinger (Harper Collins), Boston.

Fülöp, G., Hisrich, R.D. and Szegedi, K. (2000), "Business ethics and social responsibility in transition economies", Journal of Management Development, Vol. 19 No. 1, pp. 5-31.

Gallego-Alvarez, I., Manuel Prado-Lorenzo, J. and García-Sánchez, I.M. (2011), "Corporate social responsibility and innovation: a resource-based theory", Management Decision, Vol. 49 No. 10, pp. 1709-1727.

Gamal El Din, A. (2009), “A pause for self-assessment”, The Executive, January-March, p. 2.

Gbadamosi, G. (2004), "Academic ethics: what has morality, culture and administration got to do with its measurement?", Management Decision, Vol. 42 No. 9, pp. 1145-1161.

Gebba, T.R. (2015), "Corporate governance mechanisms adopted by UAE national commercial banks", Journal of Applied Finance and Banking, Vol. 5 No. 5, pp. 23-61.

Germanova, R. (2008), “Corporate social responsibility as corporate governance tool: the practice by the business in Bulgaria", August.

Ghafran, C. and O'Sullivan, N. (2013), "The governance role of audit committees: reviewing a decade of evidence", International Journal of Management Reviews, Vol. 15 No. 4, pp. 381-407.

Grant, G.H. (2003), "The evolution of corporate governance and its impact on modern corporate America", Management Decision, Vol. 41 No. 9, pp. 923-934.

Habbash, M (2016), "Corporate governance and corporate social responsibility disclosure: evidence from Saudi Arabia", Journal of Economic and Social Development, Vol. 3 No. 1, pp. 88-99.

Hassan, M. (2013), "The introduction of corporate governance codes in a transitional economy and its impact on compliance with mandatory disclosure: the case of Egypt", International Journal of Research in Business and Social Science, Vol. 2 No. 1, pp. 7-21.

Jamali, D. (2008), "A stakeholder approach to corporate social responsibility: a fresh perspective into theory and practice", Journal of Business Ethics, Vol. 82 No. 1, pp. 213-231.

Jo, H. and Harjoto, M.A. (2012), "The causal effect of corporate governance on corporate social responsibility", Journal of Business Ethics, Vol. 106 No. 1, pp. 53-72.

Kallamu, B.S. (2016), "Impact of the revised Malaysian code on corporate governance on audit committee attributes and firm performance", Turkish Economic Review, Vol. 3 No. 1, pp. 188-200. 
Kellermanns, F.W., Eddleston, K.A., Sarathy, R. and Murphy, F. (2012), "Innovativeness in family firms: a family influence perspective”, Small Business Economics, Vol. 38 No. 1, pp. 85-101.

Khalil, S., Saffar, W. and Trabelsi, S. (2015), "Disclosure standards, auditing infrastructure, and bribery mitigation", Journal of Business Ethics, Vol. 132 No. 2, pp. 379-399.

Kim, Y., Brodhag, C. and Mebratu, D. (2014), "Corporate social responsibility driven innovation", Innovation: The European Journal of Social Sciences, Vol. 27 No. 2, pp. 175-196.

Koldertsova, A. (2011), "The second corporate governance wave in the Middle East and North Africa", OECD Journal: Financial Market Trends, Vol. 2010 No. 2, pp. 219-226.

Luo, X. and Du, S. (2015), "Exploring the relationship between corporate social responsibility and firm innovation”, Marketing Letters, Vol. 26 No. 4, pp. 703-714.

Mahmood, S. (2008), "Corporate governance and business ethics for SMEs in developing countries: challenges and way forward", International Society of Business, Economics, and Ethics World Congress, July, pp. 15-18.

Nheri, O. (2014), "Economic reforms, corporate governance and privatization method as determinants in performance changes of new privatized firms: the case of MENA countries", Journal of Management \& Governance, Vol. 18 No. 1, pp. 95-127.

OECD (2015), G20/OECD Principles of Corporate Governance, OECD, Ankara.

Piesse, J., Strange, R. and Toonsi, F. (2012), "Is there a distinctive MENA model of corporate governance?", Journal of Management \& Governance, Vol. 16 No. 4, pp. 645-681.

Rexhepi, G., Kurtishi, S. and Bexheti, G. (2013), "Corporate social responsibility (CSR) and innovation - the drivers of business growth?", Procedia - Social and Behavioral Sciences, Vol. 75 No. 1, pp. 532-541.

Rossouw, G.J. (2005), "Business ethics and corporate governance in Africa”, Business \& Society, Vol. 44 No. 1, pp. 94-106.

Sacconi, L. (2012), "Corporate social responsibility and corporate governance”, Econometrica, No. 38, pp. 298-322, available at: www.econometica.it/wp/wp38.pdf

Saïdi, N. (2004), "Corporate governance in MENA countries. Improving transparency and disclosure", The Lebanese Transparency Association, Beirut, p. 81.

Salloum, C.C., Azoury, N.M. and Azzi, T.M. (2013), "Board of directors' effects on financial distress evidence of family owned businesses in Lebanon", International Entrepreneurship and Management Journal, Vol. 9 No. 1, pp. 59-75.

Samaha, K., Dahawy, K., Hussainey, K. and Stapleton, P. (2012), "The extent of corporate governance disclosure and its determinants in a developing market: the case of Egypt", Advances in Accounting, Vol. 28 No. 1, pp. 168-178.

Sariannidis, G. (2014), "Financial, governance and environmental determinants of corporate social responsible disclosure”, Management Decision, Vol. 52 No. 10, pp. 1928-1951.

Shleifer, A. and Vishny, R.W. (1997), "A survey of corporate governance", The Journal of Finance, Vol. 52 No. 2, pp. 737-783.

Trong, T.L. (2012), "Corporate social responsibility, ethics, and corporate governance", Social Responsibility Journal, Vol. 8 No. 4, pp. 547-560.

Utama, C.A. (2012), "Company disclosure in Indonesia: Corporate governance practice, ownership structure, competition and total assets", Asian Journal of Business and Accounting, Vol. 5 No. 1, pp. $75-108$.

Wadie, R. (2011), "Corporate governance in the public sector", Middle East Point of View, No. 3, pp. 51-52.

Wetzels, M., Odekerken-Schröder, G. and Van Oppen, C. (2009), "Using PLS path modeling for assessing hierarchical construct models: guidelines and empirical illustration”, MIS Quarterly, Vol. 33, pp. 177-195.

Wood, D.J. (1991), "Corporate Social Performance”, Academy of Management Review, Vol. 16 No. 4, pp. 691-718. 


\section{Further reading}

Choi, Y.K., Han, S.H. and Lee, S. (2014), "Audit committees, corporate governance, and shareholder wealth: evidence from Korea”, Journal of Accounting and Public Policy, Vol. 33 No. 5, pp. 470-489.

Yongqiang Gao, W.H. (2017), "Corporate social responsibility and employee organizational citizenship behavior: the pivotal roles of ethical leadership and organizational justice", Management Decision, Vol. 55 No. 2, pp. 294-309.
Corporate ethics, CG and CSR in MENA countries

Corresponding author

Abdul-Nasser El-Kassar can be contacted at: abdulnasser.kassar@lau.edu.lb

For instructions on how to order reprints of this article, please visit our website: 